\title{
Erratum to: Research On and Activities For Mathematically Gifted Students
}

\section{Erratum to:}

Chapter "Research On and Activities For Mathematically Gifted Students" in: F.M. Singer et al., Research On and Activities For Mathematically Gifted Students, ICME-13 Topical Surveys, DOI 10.1007/978-3-319-39450-3_1

In the original version of the book, the incorrect author name "Printer" has been changed to read as "Trinter" in reference list and citation. 